\title{
Identifying Consistent Patterns of Quality Learning Discussions in Blended Learning
}

\author{
Feifei Han ${ }^{\mathrm{a}},{ }^{*}$, Robert A. Ellis ${ }^{\mathrm{b}}$ \\ ${ }^{a}$ Centre for Research on Learning and Innovation, School of Education and Social Work, \\ Faculty of Arts and Social Sciences, Room 250, Building A35, University of \\ Sydney, Sydney, NSW 2006, Australia \\ $\mathrm{b}$ Learning and Teaching, PVC (Arts, Education and Law), 3.15A, G23, PVC (Arts, \\ Education and Law), Gold Coast campus, Griffith University, QLD 4222, Australia
}

\begin{abstract}
Adopting relational perspectives on university student learning, this research identified patterns of varying quality of learning through blended discussions. It investigated associations amongst conceptions of learning through discussions, approaches to face-to-face and online discussions, and academic achievement among two cohorts of postgraduates $(N=$ 387 and $N=184$ ) in the same business course over two consecutive years in an Australian university. Inclusion of two studies allowed an examination of the extent to which the relationships amongst variables were consistent and stable. The two studies showed logical and stable relationship amongst key variables: cohesive conceptions of learning through discussions were positively linked with deep approaches that students adopted towards discussions in class and online, which also related positively to better academic achievement. Our results suggest that university instructors should help learners see values of learning through blended discussions and explicate how the face-to-face and online discussions are integrated.
\end{abstract}

Keywords: conceptions of learning through discussions; approaches to face-to-face and online discussions; academic achievement; consistency; postgraduates

\section{Introduction}

\subsection{Learning through discussions in blended learning}

Educational researchers and curriculum designers attach important roles to learning through discussions in higher education, because discussions enable students to actively participate in the process of knowledge construction through communication (Hamann, Pollock, \& Wilson, 2012; Huerta, 2007, Vonderwell, 2003). Crucially, in the communicative process, students draw on their prior knowledge and experiences, they try to synthesise a range of perspectives as they interact with the teaching staff and their peers. Successful discussions help students co-construct knowledge in an active way, and inhibit tendencies to remain passive. The value of discussions as a way of learning has been recognized as a central component in higher education teaching and learning (Ellis \& Goodyear, 2013; Lyon \& Lagowski, 2008; Rovai, 2007).

In the last decade, learning environments in universities have been saturated with a text-based asynchronous learning tasks, which typically are integrated with face-to-face experiences of learners (Bliuc, Goodyear, \& Ellis, 2007; Garrison, 2011; Garrison, Anderson, \& Archer, 2000; Garrison \& Arbaugh, 2007; Garrison \& Vaughan, 2008; Laurillard, 2013). There is an upward trend that university courses are using online discussions to extend and elaborate the face-to-face discussions, which often take place in lectures, teaching laboratories, tutorials, and other physical learning spaces enabling the course. Discussions for learning can be undertaken either synchronously or asynchronously. In the synchronous 
discussions, students and teaching staff are copresent, such as 'real-time' electronic messaging and face-to-face discussions in class. The asynchronous discussions often take the form of electronic discussion boards, on which both students and teaching staff post written contributions about course contents, assignments, reflections, and comments. In courses which integrate online and in class experiences, discussions often involve a mixture of synchronous and asynchronous patterns.

Including online discussions in course designs provides a number of advantages which are not achievable using face-to-face discussions alone (Joubert \& Wishart, 2012; Richardson \& Ice, 2010). One of the desirable features of online discussions is that they offer greater flexibility than face-to-face discussions because students can engage with them at a time and location which suits them, they can choose to follow a particular theme in the conversation and/or, read and respond to the other students' contributions and ideas (Blankson \& KyeiBlankson, 2008; Hamann et al., 2009). Importantly, asynchronous discussions allow students to have more time to read, reflect, and critically engage with the topics than synchronous discussions. As a result, the ideas involved may benefit from more opportunities for critical thinking (Putman, Ford, \& Tancock, 2012; Williams \& Lahman, 2011).

However, not all the research points to favourable aspects of online discussions. Some researchers argue that online discussions sometimes only limit to personal information exchange (Wallace, 2003). For instance, Angeli, Valanides, and Bonk (2003) reported that the discussion board of a group of pre-service teachers contained predominantly casual conversations, and even when the contents were about intellectual engagement, they lacked appropriate reasoning and arguments. Such findings have led some educational researchers to disagree about the best course design to enable online discussions for university learning. For instance, Guiller, Durndell, and Ross (2008) postulate that face-to-face discussions should proceed online discussions as the former can provide students opportunities to brainstorm and negotiate ideas, which can then serve as role models for students to follow in subsequent online discussions. Darabi and Jin (2013) posit that students will benefit from seeing sample online posts before they create their own. Notwithstanding these differences, a significant gap remains in the literature -systematic evidence that explains why some discussions moving back and forth between face-to-face and online contexts are more successful than others for students. Uncovering the key variables that can account for quality of discussions across different classes is one of the purposes of this study.

\subsection{Relational perspectives of student learning}

Relational perspectives of student learning have systemically identified various factors which are closely related to students' qualitatively different learning outcomes (Biggs, 2011; Herrmann, Bager-Elsborg, \& McCune, 2017; Ramsden, 2003). These factors can be broadly categorized into two sets: one set focuses on factors related to students, and the other set is concerned with teaching and environmental elements (Biggs, 1999). Student factors, including students' prior experience, conceptions of learning, and how they approach learning, tend to have direct relation to quality of learning; whereas the teaching and environmental factors, including how teachers approach to teaching, how course materials are selected, organized, and presented, and whether learning occurs face-to-face, online, or both, tend to be indirectly associated with students' levels of success in learning (Entwistle, 2009).

Conceptions of learning are the ways students conceive of what the learning process is, what the learning outcomes may be, the beliefs about the nature of knowledge, and how to come to know (Ellis, Goodyear, Calvo, \& Prosser, 2008; Marton, 2014). Using phenomenography, qualitatively different variations of how learning is conceived from students' responses in interviews and open-ended questionnaires have been identified, and 
these differences can be categorized and arranged in hierarchical and logical ways (Crawford Gordon, Nicholas, \& Prosser, 1998). The conceptions typically fall into two broad categories: one sees learning as a way to develop novel concepts, integrate new concepts with existing knowledge, and restructure knowledge (i.e., cohesive conceptions); the other considers learning merely as following rules to reproduce and accumulate knowledge from pieces of information (i.e., fragmented conceptions) (Chiu, Lin, \& Tsai, 2016; Yang \& Tsai, 2010).

Different conceptions of learning are closely related to how students approach learning. Students' approaches to learning have been investigated in different disciplines and with different learning tasks, such as reading, writing, and problem solving, and inquiry (Ellis, Pardo, \& Han, 2016; Limbu \& Markauskaite, 2015; Säljö, 1979). These studies also identified qualitative variations in approaching learning which are hierarchically related. Broadly speaking, one category of approaches is oriented towards being proactive and engaging in the learning processes, in which students take initiatives (i.e., deep approaches). The other category of approaches are characterized by rote memorization, formulaic and mechanistic ways of learning, and the primary aim is to fulfil course requirements (i.e., surface approaches) (Asikainen, Parpala, Lindblom-Ylänne, Vanthournout, \& Coertjens, 2014; Edmunds \& Richardson, 2009).

Past research in face-to-face learning has consistently shown that there is a logical association between students' conceptions, approaches, and quality of learning outcomes. Students who hold cohesive conceptions tend to adopt deep approaches, and achieve relatively better outcomes; whereas fragmented conceptions tend to relate to surface approaches and poorer outcomes in learning (Goldman, Assaraf, \& Shaharabani, 2013; Zhu, Valcke, \& Schellens, 2008).

Using relational perspectives as a framework, a number of previous studies have identified variations of students' conceptions of and approaches to learning through discussions in blended contexts (e.g., Ellis \& Calvo, 2004, 2006; Ellis, Calvo, Levy, \& Tan, 2004; Ellis et al., 2008; Tsai \& Tsai, 2013, 2014). For instance, Ellis et al.'s (2004) phenomenographic research identified four categories of conceptions of learning through discussions (i.e., to understand ideas from multiple perspectives, to understand ideas, to exchange ideas, and to develop communication skills); five categories of approaches to faceto-face discussions (i.e., engaged to learn from others' experience, engaged to solve problems, engaged to finish tasks, engaged to develop communication skills, and not engaged); and four categories of approaches to online discussions (i.e., to deepen understanding, to improve understanding, to see what others do, and to fulfil subject requirements) among Australian undergraduates. Similarly, Tsai and Tsai (2013) identified four distinct conceptions of online argumentation (i.e., reflecting on and extending ideas, negotiating ideas, expressing ideas, and discussing ideas); and five approaches to online argumentation (i.e., evaluating postings and making careful reflections, getting responses for enhancing understanding, replying to postings and adding to ideas, and finding the related information) among Taiwanese undergraduates studying a business degree. The conceptions and approaches identified in these studies share similarities that these conceptions can be distinguished between cohesive and fragmented categories; and the approaches fall into deep and surface categories. While cohesive conceptions see that the learning tasks (i.e., discussions and argumentation) as valuable and meaningful ways of learning; fragmented conceptions only view the learning tasks as activities separated from learning. Likewise, students adopt deep approaches, which are engaging, to develop learning and assist conceptual understanding; whereas they use surface approaches, which are often not engaging, to merely complete the tasks without meaningful learning purposes.

Informed by the phenomenographic results, questionnaires were constructed to investigate association between conceptions and approaches in quantitative studies (e.g., 
Bliuc, Ellis, Goodyear, \& Piggott, 2010). The collective findings of the quantitative and phenomenographic studies identified logical relations between conceptions and approaches: on the one hand, cohesive conceptions display positive relations with deep approaches involving meaningful strategies; on the other hand, fragmented conceptions are positively associated with surface approaches involving mechanistic and formulaic strategies. Moreover, students who hold cohesive conceptions and report adopting deep approaches also tend to achieve relatively better academically than their counterparts, who have fragmented conceptions and report surface approaches (e.g., Bliuc et al., 2010; Ellis et al., 2008; Tsai \& Tsai, 2014).

The current study further extends this line of research with a number of aims. First, the study aimed to identify qualitative variation in learning through discussions in postgraduate education, which distinguishes itself from the previous research solely in undergraduate education. By varying level of university education, another key aim was to investigate stability and consistency of the pattern of variations which might explain differing experiences of the quality of learning through discussions. To do this, two cohorts of students who studied the same course in two consecutive academic years were investigated. The research questions guiding this study are:

What are the relational patterns of variation in the postgraduate student experience of learning through discussions and qualitatively different learning outcomes?

To what extent are the patterns consistent in the same course across two different cohorts of students in different years?

\section{Method}

\subsection{Participants}

The participants in study 1 were 387 postgraduate students enrolled in an Advanced Financial Reporting course at a large metropolitan Australian research intensive university. This cohort of students aged between 23 and $59(M=25.94)$. The participants in study 2 were 184 postgraduates who attended the same accounting course in the following academic year. The ages of the second cohort were between 26 and 55 years old $(M=30.63)$.

\subsection{The learning context}

The Advanced Financial Reporting course was a one-semester long blended learning course with a key feature of incorporating compulsory face-to-face and online discussions on a weekly basis throughout the course. Before each discussion session, the students were required to complete mandatory readings of discussion topics and questions prepared by the course coordinator. The students were expected to contribute to the discussions using knowledge gained through pre-readings and from lectures. The face-to-face discussions, which primarily took place in tutorials with a small proportion in lectures, were moderated by the course coordinator and tutors. The topics of the in class discussions placed much emphasis on case studies, which provided real world examples of the theories. To provide a guidance of approaching discussion tasks, the teaching staff modelled how to use theories to solve practical problems using a sample case study. The online discussions required students to contribute at least two posts for each topic (each post had to have a minimum length of 200 words) in a commercial Learning Management System - Blackboard. The topics of online discussions both extended and complemented face-to-face discussions. The Blackboard discussion boards were separated into two sections: section one only involved topics related to the in class discussions, and section two had topics which were not part of the in class discussions. Section one enabled students to further extend discussions of the case studies in 
the lectures and tutorials. In this section, the teaching staff made comments to questions and contents related to the case studies so that students could receive the same level of advice and feedback. To complement in class discussions, in section two, students could raise their own questions and suggest solutions to them. For section two, the teaching staff also constantly monitored the discussion board to facilitate online discussion. For instance, according to the themes of students' questions, teachers arranged them into different threads, which assisted students tracing these more easily.

The participation of discussions in the blended contexts both directly and indirectly linked to the assessments in the course. Directly, the quality of online discussions contributed to $5 \%$ of the final course mark (The marking rubrics of the online discussions were explained in details in the section "2.3.2. The learning outcome" below). Indirectly, topics of the discussions held in classes and online were the main concepts and difficult points of each week. Through discussions, students were expected to gain a more in-depth understanding of these concepts covered in the lectures and readings. Thus, discussions might help students prepare for both formative and summative assessment tasks (These tasks were explained in details in the section "2.3.2. The learning outcome" below).

The main learning objectives of the course were to familiarize students with problems encountered in reporting on complex transactions within multi-entity structures, and to develop an understanding of the solutions to a number of financial reporting problems related to multi-entity structures and corporate investments. The course used rich examples to introduce widely adopted methods and to explain technical solutions according to accounting standards and guidelines. It also aimed at developing students' ability to read and understand financial reports and to use them to make sound management decisions. The topics covered in the course included practical application of the control tests, foreign currency translation reporting, multiple subsidiaries reporting, consolidated cash flow reporting, segment reporting, reporting for joint arrangements and associates, and disclosures to related party.

\subsection{Instruments}

\subsubsection{Close-ended questionnaire}

A close-ended questionnaire, which was developed using the phenomenographic findings from previous research (Ellis \& Calvo, 2004, 2006), was used to investigate conceptions of and approaches to discussions. The questionnaire was on a 5-point Likert scales $(1=$ strongly disagree; $5=$ strongly agree). The questionnaire contained the following six scales:

Cohesive conceptions of learning through discussions scale (5 items) conceives learning through discussions as meaningful ways to deepen understanding of subject matter, to clarify thoughts, to learn about things from multiple perspectives, and to provide good opportunities to reflect on learning processes and knowledge (e.g., Discussing in this subject is like a process of reflection that allows us to better understand the things we study).

Fragmented conceptions of learning through discussions scale (7 items) considers learning through discussions as following concepts in the textbooks, winning an argument, and finding answers and solutions to assignments and tasks (e.g., The purpose of discussions in this subject is only to follow the ideas in the textbook).

Deep approaches to face-to-face discussions scale (8 items) describes using faceto-face discussions to connect future professional world and to evaluate one's thoughts (e.g., I use discussions in class as a way of evaluating the way I am thinking about a topic). 
Surface approaches to face-to-face discussions scale (4 items) describes either using face-to-face discussions to complete assignments, to remember facts, or avoiding participation as much as possible (e.g., I only discuss issues in class that help me to solve assignments).

Deep approaches to online discussions scale (8 items) uses online discussions to gauge one's understandings, to assist knowledge development, and to actively reflect upon ideas from others' posts (e.g., I find that the on-line discussions raise alternative perspectives on issues that broaden my own).

Surface approaches to online discussions scale (5 items) approaches online discussions in a way to comply with the course requirements. The approaches do not attempt to integrate discussion in face-to-face with online contexts (e.g., When I make postings on-line, I rarely think about the discussions we've had in class).

\subsubsection{The learning outcome}

We used the final course mark as the indicator of the learning outcome, which was collected for study 2 only. The final course mark was an aggregated score of five assessment tasks with a total score of 100 . Three assessments were formative, including two case studies (25\%) and quality of online discussions (5\%). The two case studies assessed students' ability to apply theory to practice in unfamiliar situations. The online discussions were marked by the following rubrics: (1) addressing both conceptual and practical issues of financial reporting; (2) generating in-depth reflections by integrating ideas from textbooks, lectures, tutorials, and students' own opinions; (3) referring to relevant accounting standards in the textbooks and other readings; (4) critically evaluating others' posts and making appropriate suggestions to peer students' problems and questions; and (5) raising meaningful questions and problems, which were able to intrigue deep and provoking reflection. The other two assessments were summative, the mid-semester (15\%) and final examinations (55\%), which assessed students' knowledge in a time-structured format. The mid-semester examination was a one-hour open book examination and the final examination was a two-hour close book examination.

\subsection{Data collection procedure}

For both study 1 and 2, we followed the human research ethical guidelines in the University to invite voluntary participation from students who were enrolled in the course. The administration of the questionnaire was near the end of the semester, and students were asked to provide their answers in relation to their learning experience in this course. Students from study 2 were also asked for the permission to access to their final course marks.

\subsection{Data analysis}

To identify the patterns of quality of learning through discussions, we carried out three analyses, which allowed us to see the integrity of the results from multiple methods. First, correlation analyses were used to examine association amongst variables at pairwise level. Second, factor analyses were performed using the $M$ scores of the conceptions and approaches scales to explore the structural relationships by identifying groups of variables that are related and variables that fall out of the group (Ellis \& Calvo, 2006; Prosser \& Trigwell, 1999). Third, at the level of student grouping, hierarchical cluster analyses using Ward's method were conducted to classify students by maximizing similar learning experience within a cluster and different learning experience between clusters. Based on the cluster membership, one-way ANOVAs were used to examine whether there were significant contrasts on conceptions, approaches, and the learning outcome (only for study 2). To 
facilitate interpretation of the results, we converted the raw scores of all the variables (i.e., $M$ scores of six scales and final course marks - only for study 2) into $z$-scores, which had $M$ s of 1 and $S D s$ of 0 , and used $z$-scores in the cluster analyses and one-way ANOVAs.

\section{Results}

Descriptive statistics and reliability of the scales are displayed in Table 1. The values of Cronbach's alpha showed acceptable reliability for the all the scales across the two cohorts of students.

\section{Table 1}

Descriptive statistics and reliability of the scales (study 1 and 2).

\begin{tabular}{lrrrrrr}
\hline variables & study $1(N=387)$ & \multicolumn{4}{c}{ study $2(N=184)$} \\
& $M$ & $S D$ & $\alpha$ & $M$ & $S D$ & $\alpha$ \\
\hline coherent conceptions of discussions & 3.83 & 0.64 & .89 & 3.92 & 0.54 & .84 \\
fragmented conceptions of discussions & 2.90 & 0.57 & .62 & 2.87 & 0.60 & .64 \\
deep approaches to face-to-face discussions & 3.54 & 0.57 & .83 & 3.60 & 0.54 & .83 \\
surface approaches to face-to-face discussions & 2.73 & 0.68 & .73 & 2.61 & 0.67 & .70 \\
deep approaches to online discussions & 3.56 & 0.52 & .82 & 3.76 & 0.58 & .88 \\
surface approaches to online discussions & 2.73 & 0.60 & .63 & 2.58 & 0.69 & .75 \\
final course marks & --- & --- & --- & 57.47 & 8.37 & --- \\
\hline
\end{tabular}

\subsection{Results of correlation analyses}

The results of correlation analyses are presented in Table 2 for study 1 . Table 2 shows that cohesive conceptions of learning through discussions scale had positive and moderate correlation with both deep approaches to face-to-face discussions $(r=.64, p<.01)$ and deep approaches to online discussions $(r=.58, p<.01)$. It had negative association with surface approaches to face-to-face $(r=-.11, p<.05)$ and online discussions $(r=-.14, p<.01)$. In contrast, the correlation between fragmented conceptions and surface approaches to face-toface $(r=.45, p<.01)$ and online discussions $(r=.34, p<.01)$ were positive and moderate. Furthermore, we observed that deep approaches to face-to-face discussions were positively and moderately associated with deep approaches to online discussions $(r=.59, p<.01)$. Likewise, surface approaches to face-to-face and online discussions scales were positively related to each other $(r=.45, p<.01)$. These results demonstrate that students who held cohesive conceptions of learning through discussions tended to adopt approaches to discussions which were more engaged in lectures, tutorials, and through the LMS; whereas students with fragmented conceptions were more likely to use surface approaches to discussions, both when they were involved in the face-to-face context, and in the context of online contributions in the discussion board.

\section{Table 2}

Results of correlation analyses (study 1).

\begin{tabular}{lllllll}
\hline variables & CC & FC & DAF & SAF & DAO & SAO \\
\hline CC & --- & & & & & \\
FC & -.02 & --- & & & & \\
DAF & $.64^{* *}$ & .08 & --- & & & \\
SAF & $-.11^{*}$ & $.45^{* *}$ & .03 & -- & & \\
DAO & $.58^{* *}$ & .05 & $.59^{* *}$ & -.07 & --- & \\
SAO & $-.14^{* *}$ & $.34^{* *}$ & -.10 & $.45^{* *}$ & -.09 & --- \\
\hline
\end{tabular}


Notes: $* * p<.01, * p<.05 . \mathrm{CC}=$ coherent conceptions, $\mathrm{FC}=$ fragmented conceptions, $\mathrm{DAF}=$ deep approaches to face-to-face discussions, $\mathrm{SAF}=$ surface approaches to face-to-face discussions, DAO = deep approaches to online discussions, and $\mathrm{SAO}=$ surface approaches to online discussions.

The results of correlation analyses for study 2 are displayed in Table 3, which demonstrates similar pairwise patterns as revealed in study 1 . Consistently, we found that cohesive conceptions were significantly and positively correlated with deep approaches to both face-to-face $(r=.67, p<.01)$ and online discussions $(r=.53, p<.01)$, and both correlation coefficients were moderate. However, cohesive conceptions were negatively and weakly correlated only with surface approaches to online discussions $(r=-.07, p<.05)$. The association between fragmented conceptions and surface approaches to face-to-face discussions were positive and were stronger $(r=.55, p<.01)$ than the one between fragmented conceptions and surface approaches to online discussions $(r=.32, p<.01)$. Similar to study 1 , the two deep approaches to discussions were positively related to each other $(r=.48, p<.01)$, and the relationship between the two surface approaches to discussions were also significant and positive $(r=.34, p<.01)$.

Table 3 also shows that the learning outcome was positively associated with cohesive conceptions $(r=.21, p<.01)$ and deep approaches to online discussions $(r=.15, p<.01)$, suggesting that students who reported having cohesive conceptions of learning through discussions tended to adopt deep approaches to discussions in face-to-face contexts, and were more likely to obtain higher course marks. We also conducted correlation analyses by excluding the quality of online discussions from the final course marks to examine if this might affect the relationship between the learning outcome and conceptions and approaches. We noticed that all the correlations remained the same, except for the correlation between final course mark and surface approaches to online discussions. These results were understandable, considering quality of online discussions only accounted for 5\% in the final course marks.

Table 3

Results of correlation analyses (study 2).

\begin{tabular}{llllllll}
\hline variables & CC & FC & DAF & SAF & DAO & SAO & FCM \\
\hline CC & --- & & & & & & \\
FC & .13 & --- & & & & & \\
DAF & $.67^{* *}$ & .05 & --- & & & & \\
SAF & -.01 & $.55^{* *}$ & -.01 & --- & & & \\
DAO & $.53^{* *}$ & .04 & $.48^{* *}$ & -.11 & --- & & \\
SAO & $-.07^{*}$ & $.32^{* *}$ & -.14 & $.34^{* *}$ & -.44 & --- & \\
FCM & $.21^{* *}$ & .12 & $.15^{*}$ & -.03 & .10 & .06 & \\
FCM (no online discussions) & $.21^{* *}$ & .12 & $.15^{*}$ & -.03 & .10 & .05 & $1.00^{* *}$ \\
\hline
\end{tabular}

Notes: $* * p<.01, * p<.05 . \mathrm{CC}=$ coherent conceptions, $\mathrm{FC}=$ fragmented conceptions, $\mathrm{DAF}=$ deep approaches to face-to-face discussions, $\mathrm{SAF}=$ surface approaches to face-to-face discussions, $\mathrm{DAO}=$ deep approaches to online discussions, $\mathrm{SAO}=$ surface approaches to online discussions, and FCM = final course marks.

Comparing the correlation coefficients across the two studies, we can see that these pairwise relationships were stable in terms of their directions and strength across the two cohorts of the postgraduates enrolled in the same accounting course in different years, indicating a consistent pattern of pairwise relations between the qualitatively different conceptions of learning through discussions and qualitatively different ways of using discussions to learn in this postgraduate level blended course.

\subsection{Results of factor analyses}


The results of factor analyses which revealed the interrelationship of groups of variables are displayed in Table 4.

\section{Table 4}

Results of factor analyses (study 1 and 2).

\begin{tabular}{|c|c|c|c|c|}
\hline \multirow[t]{2}{*}{ variables } & \multicolumn{2}{|c|}{ study 1} & \multicolumn{2}{|c|}{ study 2} \\
\hline & factor 1 & factor 2 & factor 1 & factor 2 \\
\hline coherent conceptions of discussions & .86 & & .88 & \\
\hline fragmented conceptions of discussions & & .76 & & .83 \\
\hline deep approaches to face-to-face discussions & .87 & & .86 & \\
\hline surface approaches to face-to-face discussions & & .81 & & .83 \\
\hline $\begin{array}{l}\text { deep approaches to online discussions } \\
\text { surface anproaches to online discussions }\end{array}$ & .84 & 75 & .78 & 67 \\
\hline & & & & $.6 /$ \\
\hline
\end{tabular}

Notes: study 1: $\mathrm{KMO}=.65 ;$ study $2: \mathrm{KMO}=.66$.

Both factor analyses show that students' conceptions and approaches variables fell into two factors. Factor 1 had substantial positive loadings on the three scales: cohesive conceptions of discussions (study 1: .86, study 2: .88), deep approaches to face-to-face discussions (study 1: .87, study 2: .86), and deep approaches to online discussions (study 1: .84, study 2: .78). Factor 2 had large and positive loadings on the other three scales: fragmented conceptions of discussions (study 1:.76, study 2: .83), surface approaches to face-to-face discussions (study 1: .81, study 2: .83), and surface approaches to online discussions (study 1: .75, study 2: .67).

The results of the two studies suggest that cohesive conceptions, deep approaches to face-to-face and online discussions were positively associated with each other but negatively associated with fragmented conceptions, surface approaches to discussions in both face-toface and online contexts. The similar factor patterns and strength of loadings for the two cohorts of students confirmed that the logical interrelationships among variables were consistent and stable.

\subsection{Results of cluster analyses and one-way ANOVAs}

While the correlation analyses provided evidence of how key variables were related to each other, the cluster analyses provided evidence of the distribution of the different student experiences across the population sample. The cluster analyses and one-way ANOVAs are presented in Table 5 and 6 for study 1 and 2 respectively.

Table 5.

Summary statistics of the two clusters (study 1).

\begin{tabular}{|c|c|c|c|c|c|c|c|}
\hline \multirow[t]{2}{*}{ variables } & \multicolumn{2}{|c|}{$\begin{array}{l}\text { Understanding } \\
\quad(N=233)\end{array}$} & \multicolumn{2}{|c|}{$\begin{array}{l}\text { Reproducing } \\
(N=154)\end{array}$} & \multirow[t]{2}{*}{$F$} & \multirow[t]{2}{*}{$p$} & \multirow[t]{2}{*}{$\eta^{2}$} \\
\hline & $M$ & $S D$ & $M$ & $S D$ & & & \\
\hline $\begin{array}{l}\text { coherent conceptions of } \\
\text { discussions }\end{array}$ & 0.37 & 0.71 & -0.56 & 1.12 & 99.92 & $<.01$ & .21 \\
\hline $\begin{array}{l}\text { fragmented conceptions of } \\
\text { discussions }\end{array}$ & -0.37 & 0.85 & 0.57 & 0.94 & 102.21 & $<.01$ & .21 \\
\hline $\begin{array}{l}\text { deep approaches to face-to-face } \\
\text { discussions }\end{array}$ & 0.31 & 0.84 & -0.47 & 1.04 & 65.58 & $<.01$ & .15 \\
\hline $\begin{array}{l}\text { surface approaches to face-to-face } \\
\text { discussions }\end{array}$ & -0.39 & 0.87 & 0.59 & 0.88 & 117.99 & $<.01$ & .24 \\
\hline
\end{tabular}


deep approaches to online

discussions

surface approaches to online

discussions

$\begin{array}{rrrrrrr}0.38 & 0.68 & -0.57 & 1.13 & 104.48 & <.01 & .21 \\ -0.36 & 0.82 & 0.55 & 1.00 & 96.50 & <.01 & .20\end{array}$

Table 5 shows that the students in study 1 were clustered into two groups and the differences of all the six variables were significant between cluster 1 and 2: coherent conceptions, $F(1,386)=99.92, p<.01, \eta^{2}=.21$; fragmented conceptions, $F(1,386)=$ $102.21, p<.01, \eta^{2}=.21$; deep approaches to face-to-face discussions, $F(1,386)=65.58, p$ $<.01, \eta^{2}=.15$; surface approaches to face-to-face discussions, $F(1,386)=117.99, p<.01$, $\eta^{2}=.24$; deep approaches to online discussions, $F(1,386)=104.48, p<.01, \eta^{2}=.21$; and surface approaches to online discussions, $F(1,386)=96.50, p<.01, \eta^{2}=.20$. Among 387 students, 233 students self-reported having more cohesive conceptions $(M=0.37)$ and less fragmented conceptions $(M=-0.37)$, adopted more deep approaches $(M=0.31)$ and less surface approaches to face-to-face discussions $(M=-0.39)$, and they also used more deep approaches to online discussions $(M=0.38)$, and applied less surface approaches to online discussions $(M=-0.36)$, than 154 students, who held more fragmented conceptions $(M=$ $0.57)$, adopted more surface approaches to face-to-face discussions $(M=0.59)$ and online discussions $(M=0.55)$.

Table 6.

Summary statistics of the two clusters (study 2).

\begin{tabular}{lccccccc}
\hline variables & \multicolumn{2}{c}{$\begin{array}{l}\text { Understanding } \\
(N=61)\end{array}$} & \multicolumn{2}{c}{$\begin{array}{l}\text { Reproducing } \\
(N=123)\end{array}$} & $F$ & $p$ & $\eta^{2}$ \\
& $M$ & $S D$ & $M$ & $S D$ & & & \\
\hline $\begin{array}{l}\text { coherent conceptions of } \\
\text { discussions }\end{array}$ & 0.64 & 0.78 & -0.31 & 0.95 & 46.56 & $<.01$ & .20 \\
$\begin{array}{l}\text { fragmented conceptions of } \\
\text { discussions }\end{array}$ & -0.33 & 1.18 & 0.16 & 0.86 & 10.47 & $<.01$ & .05 \\
$\begin{array}{l}\text { deep approaches to face-to-face } \\
\text { discussions }\end{array}$ & 0.68 & 0.81 & -0.34 & 0.91 & 55.36 & $<.01$ & .23 \\
$\begin{array}{l}\text { surface approaches to face-to-face } \\
\text { discussions }\end{array}$ & -0.55 & 0.92 & 0.27 & 0.92 & 32.82 & $<.01$ & .15 \\
$\begin{array}{l}\text { deep approaches to online } \\
\text { discussions }\end{array}$ & 0.67 & 0.76 & -0.33 & 0.94 & 52.92 & $<.01$ & .23 \\
$\begin{array}{l}\text { surface approaches to online } \\
\text { discussions }\end{array}$ & -0.78 & 0.81 & 0.39 & 0.85 & 80.49 & $<.01$ & .31 \\
final course marks & 0.39 & 0.98 & -0.19 & 0.96 & 14.94 & $<.01$ & .08 \\
\hline
\end{tabular}

Table 6 presents the results of cluster analyses and one-way ANOVAs for study 2, which included students' learning outcomes. The results exhibited similar pattern as in study 1 for the conceptions and approaches variables. The two clusters differed significantly on these variables: cohesive conceptions, $F(1,183)=46.56, p<.01, \eta^{2}=.20$; fragmented conceptions, $F(1,183)=10.47, p<.01, \eta^{2}=.05$; deep approaches to face-to-face discussions, $F(1,183)=55.36, p<.01, \eta^{2}=.23$; surface approaches to face-to-face discussions, $F(1,183)$ $=32.82, p<.01, \eta^{2}=.15$; deep approaches to online discussions, $F(1,183)=52.92, p<.01$, $\eta^{2}=.23$; and surface approaches to online discussions, $F(1,183)=80.49, p<.01, \eta^{2}=.31$. The learning outcome variable showed significant contrasts between the two clusters, $F$ (1, $183)=14.94, p<.01, \eta^{2}=.08$, which was aligned with the variations in the conceptions and approaches. 
Among 184 students, 66 students in cluster 1 had relatively higher cohesive conceptions $(M=0.64)$, approached discussions at deeper level in face-to-face $(M=0.68)$ and online $(M=0.67)$ modes, and were more likely to obtain better learning results $(M=$ $0.39)$, than 123 students in cluster 2 , who reported having more fragmented conceptions $(M=$ $0.16)$, used more surface approaches to both face-to-face $(M=0.27)$ and online $(M=0.39)$ discussions, and tended to have poorer academic performance $(M=-0.19)$.

Across the two studies, as reflected in students' responses to the questionnaire items, we found that cluster 1 students had higher cohesive conceptions, which saw learning through discussions as improving understanding of the subject matter; at the same time, approached discussion tasks by connecting theories to real problems in their professions, and by actively relating contents in lectures and tutorials to the themes of online discussions. These features of learning experience can be described as learning through discussions with an aim of "Understanding".

In contrast, cluster 2 students exhibited a pattern of learning experience which had more features at a surface level. From their responses to the questionnaire, it seemed that they did not see the important role of discussions in the learning of this accounting course, but merely followed what they were required to do by participating in the class discussions. They contributed to discussions mainly for finding solutions to the assignments or as a convenient way to finish a learning task. In the online discussions, cluster 2 students seemed not to take opportunities to critically reflect on the concepts and ideas raised in the face-to-face discussion, neither did they use their peers' posts to help them evaluate their own learning. The conceptions they held and the approaches they used were mostly concerned with "Reproducing" knowledge and facts. As revealed in study 2, Understanding and Reproducing students also differed significantly in terms of the final marks of the course, in which learning through discussions was a key feature of the course design.

\section{Discussion}

Research using relational perspectives on student learning has been extended to investigate student experience of learning in blended course designs (Ellis \& Bliuc, 2016; Limbu \& Markauskaite, 2015). The proliferation of blended experiences of learning in higher education sector means that the use of the online environment is now a ubiquitous aspect of university education. Consequently, activities such as learning through blended discussions are being integrated as a key part of students' learning experience, but little is known about students' strategies and intent online and how these integrate with their approaches in class. This is one of the motivations for this study.

A related and broader motivation for this study is identifying relatively stable variables in blended course experiences which account for variation in the quality of student learning outcomes when students are expected to move back and forth between online and in class contexts. In blended course designs across different cohorts, disciplines, and levels of education, it is very difficult to identify variables which are transferable across contexts as not much is known about how different tool sets may interact with students' approaches, and how the combination of these contributes either directly or indirectly to differences in the outcomes.

Consistent with previous research into the undergraduate experience in Australian contexts (e.g., Ellis \& Calvo, 2004; Ellis et al., 2008), our results show that postgraduate accounting students displayed qualitative variation in how they viewed learning through discussions: some students viewed discussions beyond a simplistic concept of them as an only type of learning task. For these students, they perceived discussion processes as a way to clarify their own thoughts, to consolidate their arguments, and to learn from others. They 
considered the whole processes helped them absorb new knowledge and concepts. In contrast, some other students limited the use of their discussions most likely because they regarded them as a mechanistic process, which had little contribution to helping them fundamentally understand the key concepts of their course. Such distinction between cohesive and fragmented conceptions, and deep and surface approaches, has also been identified among undergraduate students' learning in a similar learning task - online argumentation in other cultural contexts (Tsai \& Tsai, 2013, 2014).

The results of our study also demonstrate logical associations amongst qualitative variation in conceptions of discussions, approaches to discussions (both online and face-toface), and academic achievement (achievement was only in study 2). These associations were revealed at the level of variables which point towards a model for quality discussions in blended contexts, and at the level of sub-groups within the population sample. The consistency of the results across multiple statistical methods, including correlation, factor, cluster, and ANOVA contributes to the robustness of the findings. The use of multiple methods of statistical analysis also permits the associations to be described at different levels and provides a more comprehensive picture than a single method might be able to do.

The consistency of the results amongst variables in all the three analyses shows that both the direction and strength of the associations resemble each other in the two studies, demonstrating the stability of the relationship between the conceptions and approaches variables in experience of learning through blended discussions at the postgraduate level. We were able to identify two clusters of students within each study. One cluster of students who perceived discussions as a way to deepen understanding of new ideas (cohesive conceptions) reported using discussions in a meaningful way to help them understand topics and concepts covered in the course (deep approaches). The other cluster of students, saw discussions mainly as a requirement and a formulaic way of learning (fragmented conceptions), and tended to approach discussions in an equally simplistic way both online and in class (surface approaches).

Our results of the interrelated pattern amongst the variables confirm the results found with undergraduates in business (e.g., Tsai \& Tsai, 2013 - conceptions and approaches; Tsai \& Tsai, 2014 - conceptions and achievement) and in other academic disciplines (e.g., Bliuc et al., 2010; Ellis \& Calvo, 2004; Ellis et al., 2008), and extend the associations into the experience of learning of postgraduate students, who are relatively more professionally mature with various levels of work experience. Despite the consistent patterns amongst variables across the two cohorts of postgraduates, the interpretation of the research results was limited to a single course in the business discipline at an Australian university. In order for the results to be generalized, studies into multiple courses and in various educational contexts are required.

\section{Implications for teaching practice}

These results have important implications for guiding teaching practice. Since discussions are a fundamental strategy for knowledge co-construction at university (Hamann et al., 2012), university teachers often value discussions in the learning processes as a way of engaging students in class and online. However, the results of our study show that simply providing discussions to students in their learning is insufficient. Not all the students were able to recognize the value of discussions for their learning or approached discussions in a coherent way across the face-to-face and online contexts. In order for students to benefit from discussions, the results suggest that it is necessary to assist students in understanding the intent and benefits of discussions as a way to learn so that they can make the most of them. Our results of association between cohesive conceptions and deep approaches obtained from 
students' responses to the questionnaire may imply that by shifting students' fragmented conceptions of learning through discussions to more cohesive conceptions, they may start to seize the opportunities of in class and online discussions to develop their learning of the subject matter. To emphasise the idea of cohesive conceptions of learning through discussions, students should be encouraged to think more about how to use discussions to help them learn, how to critically reflect on the perspectives of others through reading and commenting on fellow students' online contributions, and how to use others' ideas in the discussions to evaluate their own. As indicated by Tsai and Tsai's (2014) experimental study, using scaffolding teaching approaches may be particular effective to improve quality of discussions. This could be achieved by posting some scaffolding questions under different discussion themes in the online discussion boards. Then teachers may explicitly point out relevant theories and accounting standards which are needed in discussing the practice in financial reporting. The teaching staff may also want to present high quality comments on students' posts, and decompose a high quality comment by highlighting the essential elements in it. These can serve as models for students' to make high quality comments on each other's posts.

Furthermore, not every student is able to see how discussions in the face-to-face and online contexts are related to each other as reflected in their answers to the questionnaire. For effective learning through discussions to occur in blended course designs, it seems to be necessary to maintain coherence between in class and online discussions. Thus, in the online discussion board, teachers can summarize the topics and ideas generated in the class as a lead-in to the discussion online, so that students can see the relevance between in class and online discussions.

Much more research is required to understand what students think they are learning through discussions and how they learn when the tasks in their courses require them to move back and forth between physical and virtual spaces. Discovering variables which can explain variations in the quality of learning through tasks split across tangible and intangible learning contexts is becoming increasingly important for those concerned about the quality of university learning. To address these concerns, future studies my extend the current research by including variables, such as students' perceptions of the blended learning environment and samples of online posts to see the interrelations between conceptions, approaches, perceptions, and the features of online posts.

\section{Acknowledgement}

Funding: This work was supported by the Australian Research Council [DP150104163].

\section{References}

Angeli, C., Valanides, N., \& Bonk, C. (2003). Communication in a web-based conferencing system: the quality of computer mediated interactions. British Journal of Educational Technology, 34(1), 31-43.

Asikainen, H., Parpala, A., Lindblom-Ylänne, S., Vanthournout, G., \& Coertjens, L. (2014). The development of approaches to learning and perceptions of the teaching-learning environment during bachelor level studies and their relation to study success. Higher Education Studies, 4(4), 24-36.

Biggs, J. (1999). What the student does: Teaching for enhanced learning. Higher Education Research and Development, 18(1), 57-75. 
Biggs, J. (2011). Teaching for quality learning at university: What the student does. London: McGraw-Hill.

Blankson, J., \& Kyei-Blankson, L. (2008). Nontraditional students' perception of a blended course: Integrating synchronous online discussion and face-to-face instruction. Journal of Interactive Learning Research, 19(3), 421-438.

Bliuc, A., Ellis, R. A., Goodyear, P., \& Piggott, L. (2010). Learning through face-to-face and online discussions: Associations between students' conceptions approaches and academic performance in political science. British Journal of Educational Technology, $41,512-524$.

Bliuc, A., Goodyear, P., \& Ellis, R. A. (2007). Research focus and methodological choices in studies into students' experiences of blended learning in higher education. Internet and Higher Education, 10(4), 231-244.

Chiu, Y., Lin, T., \& Tsai, C. (2016). The conceptions of learning science by laboratory among university science-major students: Qualitative and quantitative analyses. Research in Science and Technological Education, 34, 359-377.

Crawford, K., Gordon, S., Nicholas, J., \& Prosser, M. (1998). University mathematics students conception of mathematics. Studies in Higher Education, 23, 87-94.

Darabi, A., \& Jin, L. (2013). Improving the quality of online discussion: The effects of strategies designed based on cognitive load theory principles. Distance Education, 34(1), 21-36.

Edmunds, R., \& Richardson, J. T. (2009). Conceptions of learning approaches to studying and personal development in UK higher education. British Journal of Educational Psychology, 79(2), 295-309.

Ellis, R. A., \& Bliuc, A. (2016). An exploration into first-year university students' approaches to inquiry and online learning technologies in blended environments. British Journal of Educational Technology, 47(5), 970-980.

Ellis, R. A., \& Calvo, R. A. (2004). Learning through discussions in blended environments. Educational Media International, 40, 263-274.

Ellis, R. A., \& Calvo, R. A. (2006). Discontinuities in university student experiences of learning through discussions. British Journal of Educational Technology, 37, 55-68.

Ellis, R. A., \& Calvo, R. A., Levy, D., \& Tan, K. (2004). Learning through discussions. Higher Education Research and Development, 23, 73-93.

Ellis, R. A., \& Goodyear, P. (2013). Students' experiences of E-learning in higher education: The ecology of sustainable innovation. London: Routledge.

Ellis, R. A., Goodyear, P., Calvo, R. A., \& Prosser, M. (2008). Engineering students' conceptions of and approaches to learning through discussions in face-to-face and online contexts. Learning and Instruction, 18, 267-282.

Ellis, R. A., Pardo, A., \& Han, F. (2016). Quality in blended learning environments significant differences in how students approach learning collaborations. Computers and Education, 102, 90-102.

Entwistle, N. (2009). Teaching for understanding at university: Deep approaches and distinctive ways of thinking. Eastbourne: Palgrave Macmillan.

Garrison, D. R. (2011). E-learning in the 21st century: A framework for research and practice. Abingdon: Taylor and Francis.

Garrison, D. R., Anderson, T., \& Archer, W. (2000). Critical inquiry in a text-based environment: Computer conferencing in higher education. Internet and Higher Education, 2(2-3), 87-105.

Garrison, D. R., \& Arbaugh, J. B. (2007). Researching the community of inquiry framework: Review, issues, and future directions. Internet and Higher Education, 10(3), 157-172 
Garrison, D. R., \& Vaughan, N. D. (2008). Blended learning in higher education: Framework principles and guidelines. San Francisco, CA: John Wiley and Sons.

Goldman, D., Assaraf, O. B., \& Shaharabani, D. (2013). Conceptions of biology and approaches to learning of first year biology students: Introducing a technique for tracking changes in learner profiles over time. International Journal of Science Education, 35(3), 515-545.

Guiller, J., Durndell, A., \& Ross, A. (2008). Peer interaction and critical thinking: Face-toface or online discussion? Learning and instruction, 18(2), 187-200.

Hamann, K., Pollock, P. H., \& Wilson, B. M. (2012). Assessing student perceptions of the benefits of discussions in small-group large-class and online learning contexts. College Teaching, 60(2), 65-75.

Herrmann, K. J., Bager-Elsborg, A., \& McCune, V. (2017). Investigating the relationships between approaches to learning learner identities and academic achievement in higher education. Higher Education, 74(3): 385-400.

Huerta, J. C. (2007). Getting active in the large lecture. Journal of Political Science Education, 3(3). 237-249.

Joubert, M., \& Wishart, J. (2012). Participatory practices: Lessons learnt from two initiatives using online digital technologies to build knowledge. Computers and Education, 59(1), $110-119$.

Laurillard, D. (2013). Rethinking university teaching: A conversational framework for the effective use of learning technologies. London: Routledge.

Limbu, L., \& Markauskaite, L. (2015). How do learners experience joint writing: University students' conceptions of online collaborative writing tasks and environments. Computers and Education, 82, 393-408.

Lyon, D. C., \& Lagowski, J. J. (2008). Effectiveness of facilitating small-group learning in large lecture classes. Journal of Chemical Education, 85(11), 1571-1576.

Marton, F. (2014). Necessary conditions of learning. London: Routledge.

Prosser, M., \& Trigwell, K. (1999). Understanding learning and teaching: The experience in higher education. Buckingham: SRHE and Open University Press.

Putman, S. M., Ford, K., \& Tancock, S. (2012). Redefining online discussions: Using participant stances to promote collaboration and cognitive engagement. International Journal of Teaching and Learning in Higher Education, 24(2), 151-167.

Ramsden, P. (2003). Learning to teach in higher education. London: Routledge.

Richardson, J. C., \& Ice, P. (2010). Investigating students' level of critical thinking across instructional strategies in online discussions. Internet and Higher Education, 13(1-2), $52-59$.

Rovai, A. P. (2007). Facilitating online discussions effectively. Internet and Higher Education, 10(1), 77-88.

Säljö, R. (1979). Learning about learning. Higher Education, 8(4), 443-451.

Tsai, P. S., \& Tsai, C. C. (2013). College students' experience of online argumentation: Conceptions, approaches and the conditions of using question prompts. Internet and Higher Education, 17, 38-47.

Tsai, P. S., \& Tsai, C. C. (2014). College students' skills of online argumentation: The role of scaffolding and their conceptions. Internet and Higher Education, 21, 1-8.

Vonderwell, S. (2003). An examination of asynchronous communication experiences and perspectives of students in an online course: A case study. Internet and Higher Education, 6(1), 77-90.

Wallace, R. M. (2003). Online learning in higher education: A review of research on interactions among teachers and students. Education, Communication and Information, 3(2), 241-280. 
Williams, L., \& Lahman, M. (2011). Online discussion student engagement and critical thinking. Journal of Political Science Education, 7(2), 143-162.

Yang, Y. F., \& Tsai, C. C. (2010). Conceptions of and approaches to learning through online peer assessment. Learning and Instruction, 20(1), 72-83.

Zhu, C., Valcke, M., \& Schellens, T. (2008). A cross-cultural study of Chinese and Flemish university students: Do they differ in learning conceptions and approaches to learning? Learning and Individual Differences, 18(1), 120-127. 